\title{
Post-Genomics and Vaccine Improvement for Leishmania
}

\author{
Negar Seyed*, Tahereh Taheri and Sima Rafati \\ Department of Immunotherapy and Leishmania Vaccine Research, Pasteur Institute of Iran, Tehran, Iran
}

Leishmaniasis is a parasitic disease that primarily affects Asia, Africa, South America, and the Mediterranean basin. Despite extensive efforts to develop an effective prophylactic vaccine, no promising vaccine is available yet. However, recent advancements in computational vaccinology on the one hand and genome sequencing approaches on the other have generated new hopes in vaccine development. Computational genome mining for new vaccine candidates is known as reverse vaccinology and is believed to further extend the current list of Leishmania vaccine candidates. Reverse vaccinology can also reduce the intrinsic risks associated with

OPEN ACCESS

Edited by:

Albert Descoteaux Institut National de la Recherche

Scientifique - Institut

Armand-Frappier, Canada

Reviewed by:

Nathan Peters,

National Institute of Allergy and Infectious Diseases, USA

Simona Stäger,

Institut National de la Recherche

Scientifique - Institut

Armand-Frappier, Canada

*Correspondence:

Negar Seyed

negarse@gmail.com

Specialty section:

This article was submitted to

Infectious Diseases,

a section of the journal

Frontiers in Microbiology

Received: 15 July 2015 Accepted: 21 March 2016

Published: 06 April 2016

Citation:

Seyed N, Taheri T and Rafati S (2016) Post-Genomics and Vaccine Improvement for Leishmania.

Front. Microbiol. 7:467.

doi: 10.3389/fmicb.2016.00467 live attenuated vaccines. Individual epitopes arranged in tandem as polytopes are also a possible outcome of reverse genome mining. Here, we will briefly compare reverse vaccinology with conventional vaccinology in respect to Leishmania vaccine, and we will discuss how it influences the aforementioned topics. We will also introduce new in vivo models that will bridge the gap between human and laboratory animal models in future studies.

Keywords: Leishmania, reverse vaccinology

\section{LEISHMANIASIS: THE PROBLEM}

Leishmaniasis is caused by flagellated protozoan parasites in the Leishmania genus. The parasite's life cycle includes two developmental stages, that is, the flagellated, motile "promastigote" and the non-motile "amastigote." The amastigote resides and propagates within phagolysosomal vesicles of the host's macrophages. Different sandfly species from the genera Phlebotomus or Lutzomyia transmit the parasite to human. Factors such as the parasite number, species and site of invasion, sandfly saliva, host-derived factors affecting immune-competency and the host-parasite interaction determine the severity of disease (Rodrigues et al., 2014).

Cutaneous leishmaniasis (CL) is a self-limiting infection and most often heals without any intervention. Efficient cellular immune responses control the parasite burden and amelioration. However, healing might proceed very slowly, lasting for months and eventually ending in disfiguring scars. Ulcerated lesions do not always heal despite conventional treatments (Reithinger et al., 2007). By contrast, diffuse cutaneous leishmaniasis (DCL), which is caused by Leishmania mexicana complexes in Brazil and Venezuela, is distinguished by producing multiple parasitefilled nodules all over the body. These nodules are not self-limiting, and they heal roughly without intervention. Skin tests with parasite proteins turn out negative, which is a direct manifestation of sub-optimal cellular responses (Convit et al., 1962). Mucocutaneous Leishmaniasis (MCL) is also a non-healing problem that is secondary to cutaneous infection with specific parasite species (especially $L$. braziliensis). Parasite invasion from the skin into the nasopharyngeal mucosa causes 
vast tissue destruction with irreversible disfiguration. A failure in the proper immune response regulation is responsible for the presence of few or no parasites at the lesion site (Faria et al., 2005).

There are 500,000 new cases per year of Visceral Leishmaniasis (VL), and it is fatal if left untreated, especially in children. Leishmania co-infection with HIV has further increased mortality rates. Immune suppression concomitant with the systemic dissemination of the parasite into visceral organs debilitates patient because of the severe internal bleeding and anemia. In South Asia and East Africa, anthroponotic VL is caused by L. donovani. In the Mediterranean basin, Central and South America, zoonotic disease is caused by L. infantum, with dogs as the primary reservoirs (Chappuis et al., 2007). Post-kalaazar Dermal Leishmaniasis (PKDL) is a complication of VL that appears as dermal nodules a few years later in VL-recovered patients in India, Nepal, and Sudan. The nodules from these patients are full of parasites, and as is the case for DCL, these nodules are very important for the transmission of the disease (Zijlstra et al., 2003).

The latest epidemiological data show that leishmaniasis is a serious global problem (Alvar et al., 2012). Despite all efforts to control it, the incidence of this disease is rising primarily because of urbanization, migration, drug resistance, and coinfection with the HIV virus (Okwor and Uzonna, 2013). The current form of control relies on chemotherapy to alleviate the disease and on vector control to reduce transmission. Although a few therapeutic chemicals are now available, including antimonials, amphotericin-B (as deoxycholate or in liposomal form), paromomycin and miltefosine, some problems such as high toxicity, variable efficacy, inconvenient treatment schedules, costs and above all, drug resistance, still remain to be addressed (Croft and Olliaro, 2011). Vector control is also a difficult task because sandflies are adapted to many different micro-landscapes (Kishore et al., 2006). Therefore, an efficient prophylactic vaccine is desperately needed in addition to new drug development. Three different generations of vaccines besides leishmanization have been the subjects of massive investigations. Among the options, live attenuated and multi-subunit vaccines are more attractive (Alvar et al., 2013; Mutiso et al., 2013).

\section{IMMUNE CORRELATES OF THE DISEASE: CD4 ${ }^{+}$AND CD8 $^{+}{ }^{+}$CELLS AND REGULATION}

The characterization of the immune response in murine CL models that were infected with $L$. major has thus far answered some questions about susceptibility or resistance to Leishmania infection. Leishmania parasites are obligatory intracellular microorganisms. Amastigotes are sensitive to toxic oxygen and nitrogen metabolites of activated macrophages. In murine CL (C57BL/6 model), a Th1-mediated immune response by $\mathrm{CD}^{+} \mathrm{T}$ cells potentially activates macrophages primarily through IFN- $\gamma$ production (Belkaid et al., 2000). Experiments by the Darrah group showed that the degree of protection against L. major after a needle challenge in vaccinated C57BL/6 mice depends on the frequency at which multifunctional $\mathrm{CD}^{+} \mathrm{T}$ cells are capable of simultaneously producing IFN- $\gamma$, TNF and IL-2 (Darrah et al., 2007). However, (Peters et al., 2014) showed that $\mathrm{CD} 44^{+} \mathrm{CD}_{62 \mathrm{~L}^{-}}$T-bet ${ }^{+} \mathrm{Ly}_{6 \mathrm{C}}{ }^{+}$T- effector cells that are shortlived in the absence of infection and produce only IFN- $\gamma$ play the key role in immunity against secondary infection by sandfly challenge. Persistent parasites after healing of primary infection are responsible for induction of these effector cells that are rapidly recruited to infection site early after secondary challenge (Peters et al., 2014). The persistent production of IL-12 by dendritic cells during active infection is indispensable for the polarization and maintenance of the Th1 response (Park et al., 2000). However, the predominance of anti-inflammatory Th2 cytokines such as IL-4, IL-5, and IL-13 suppress efficient Th1 polarization and macrophage activation, thereby enhancing disease progression (Liu and Uzonna, 2012).

Although leishmaniasis is an intracellular infection, the contribution of $\mathrm{CD}^{+}$T-cells as immune correlates of the disease upon primary infection remained to be addressed (Wang et al., 1993; Huber et al., 1998) until the data from a low-dose experimental challenge in both $\mathrm{Balb} / \mathrm{c}$ and $\mathrm{C} 57 \mathrm{BL} / 6$ mice were extrapolated. The data from Balb/c mice that were infected by a low-dose challenge were controversially $\mathrm{CD}^{+}$ T-cell dependent, but these mice were able to elevate the Th1type immune response and control the primary and secondary infections (Doherty and Coffman, 1996; Menon and Bretscher, 1996; Courret et al., 2003). However, data from C57BL/6 mice clearly indicated that $\mathrm{CD}^{+}{ }^{+} \mathrm{T}$-cells contribute to $\mathrm{CL}$ control. $\mathrm{CD}^{+} \mathrm{T}$-cell depletion at primary infection abolished resistance in C57BL/6 mice that were infected intra-dermally with 1001,000 metacyclic promastigotes (an approximation of a lowdose natural infection) (Belkaid et al., 2002b). Uzonna et al. (2004) further noted that the IFN- $\gamma$ secreted by CD8 ${ }^{+}$T-cells is important for directing early Th2-type responses toward Th1 and for establishing protection, which will end in a long-term memory that protects against subsequent infections (Okwor et al., 2014). The protective function of antigen-specific $\mathrm{CD}^{+} \mathrm{T}$ cells is used not only for IFN- $\gamma$ production but also for the cytolysis of infected host cells that are defective in intracellular killing. Mice that are deficient in Fas or Fas ligands cannot eliminate L. major despite the enhanced production of nitric oxide (Huang et al., 1998). IL-10 is an important regulatory cytokine, and it plays a key role in immune response regulations in murine CL. Different cell types are responsible for IL-10 production, including $\mathrm{CD}^{+}{ }^{+} \mathrm{CD} 25^{+}$regulatory T cells (Belkaid et al., 2002a) and $\mathrm{CD}^{+}{ }^{+} \mathrm{CD}^{-} 5^{-}$Foxp3 $^{-}$cells (Anderson et al., 2007; Pagan et al., 2013). IL-10 is the most important cytokine for parasite persistence after the primary infection heals (Belkaid et al., 2001).

In human CL, a clear Th1 or Th2-polarized immune response is never observed. However, an inflammatory profile is crucial for disease control and an anti-inflammatory profile exacerbates the condition. The $\mathrm{CD}^{+}{ }^{+} \mathrm{T}$ cells are the primary contributors to pro-inflammatory cytokine production. Interspecies differences must not be neglected. Some new world species such as L. mexicana and L. amazonensis require a more robust Th1 immune response in comparison with that of L. major (McMahon-Pratt and Alexander, 2004). The CD8 ${ }^{+} \mathrm{T}$ cells and 
IL-10 that are produced by different cell types are also primary factors, and they play a dual role in human CL. CD8 ${ }^{+} \mathrm{T}$ cells contribute to the differentiation of Th1 responses during the early events of parasite infection (Pompeu et al., 2001). After the disease is cured, the $\mathrm{CD}^{+} \mathrm{T}$ cells can produce IFN- $\gamma$ and participate in the healing process (Mohajery et al., 2007). IL-10 is also produced by CL patients and is responsible for downregulating inflammatory responses, primarily those induced by IFN- $\gamma$. The presence of regulatory $\mathrm{T}$ cells in lesions from CL patients has already been described (Campanelli et al., 2006). $\mathrm{CD}^{+} \mathrm{T}$ cells and anti-inflammatory IL-10 and TGF- $\beta$ cytokines are also responsible for immunopathology in leishmaniasis. The highest parasite loads are found in early human CL lesions (Kumar et al., 2009). Experimentally, the peak parasite load has been observed just prior to L. major lesion development (Belkaid et al., 2000), which supports the idea that immunemediated skin inflammation leads to ulceration rather than a direct tissue damaging effect from the parasites (Nylen and Eidsmo, 2012). This finding is consistent with findings on chronic Leishmania infections such as MCL, DCL, and PKDL. MCL (Faria et al., 2009; Novais et al., 2013; Santos Cda et al., 2013 ) is characterized by the immunologic hyperactivity of $\mathrm{CD}^{+}$and $\mathrm{CD}^{+} \mathrm{T}$ cells (because of low $\mathrm{IL}-10$ reactivity), tissue destruction, and a low parasite burden. DCL (Nylen and Eidsmo, 2012) and PKDL (Saha et al., 2007) are associated with suppressed immune responses from sustained IL-10/TGF- $\beta$ production and high parasite loads without ulceration and tissue destruction.

The experimental VL shows almost the same results as the CL, although the same Th1/Th2 polarization is not clearly defined in experimental VL. Resistance to infection is Th1 responsedependent in the presence of IL-12. CD $4^{+} / \mathrm{IFN}-\gamma^{+} \mathrm{T}$ cells induced in liver are essential for parasite persistence in liver and resistance to VL reinfection in C57BL/6 mice model (Bunn et al., 2014). Recently Romano et al. (2015) have demonstrated a cross reactive immunity induced by $\mathrm{CD} 4^{+} / \mathrm{Ly} 6 \mathrm{C}^{+} / \mathrm{IFN}-\gamma^{+}$ $\mathrm{T}$ cells between $L$. major induced $\mathrm{CL}$ and $L$. infantum induced $\mathrm{VL}$, again bolding the role of these cells this time in memory response against VL. However, studies using IL- $4^{-/-}$and IL$4 \mathrm{R}^{-/-}$mice show that IL-4 signaling is also important for parasite clearance in the spleen and liver (Stäger et al., 2003). $\mathrm{CD}^{+} \mathrm{T}$ cells play a clear role in murine models of VL. They contribute to granuloma formation in the liver (to sequester the parasite inside macrophages). Their contribution is both proinflammatory cytokine production and the cytolysis of infected cells (Tsagozis et al., 2003). Joshi et al. (2009) showed that CD8 ${ }^{+}$ $\mathrm{T}$ cells are exhausted during $L$. donovani infection in murine models, and that the PD1/PDL-1 pathway blockade restores the capacity of these cells to control the parasite load. The IL-10 is very important in experimental VL. The blockade of the IL-10/IL-10R pathway promotes parasite clearance (to near complete resolution) in experimental models of VL (Murray et al., 2002). In human VL, the Th1 response alone is insufficient for controlling the disease, and other factors also contribute to determine the disease outcome (Singh et al., 2012). CD8 ${ }^{+}$T cell exhaustion and dysfunction has been observed in the presence of high IL-10 (Gautam et al., 2014). IL-10 is primarily produced by cells other than $\mathrm{CD} 4{ }^{+} \mathrm{CD} 25^{+}$regulatory T cells (Nylen et al., 2007).

Evidently, an immunological memory after Leishmania infection is achievable: the complete resolution of the disease results in lifelong protection. Healing from the primary infection both in mice and humans is followed by a chronic state of parasite persistence and is associated with a powerful cell-mediated immune response that rapidly deals with early immune-modulatory events at infected sandfly bite sites (Peters et al., 2009). Residual persistence is a critical factor, and the sterile cure fails to protect against further challenges (Belkaid et al., 2001; Uzonna et al., 2001; Zaph et al., 2004). The CD4 ${ }^{+}$ effector memory and central memory $\mathrm{T}$ cells are two wellknown components of immunity to reinfection (von Stebut, 2007). Effector memories (but not central memories; Zaph et al., 2004) owe their persistence to residual tissue parasites. IL-10 is required to suppress the anti-parasitic function of macrophages to maintain a small amount of parasites. Studies have shown that immunity to reinfection is compromised in IL-10 ${ }^{-/-}$mice (Belkaid et al., 2002a). Recently published data also attribute the establishment of an effective memory response to skin-resident memory CD4 ${ }^{+} \mathrm{T}$ cells (Gebhardt et al., 2013). Long after the resolution of the primary Leishmania infection, these $\mathrm{T}$ cell subsets are still detectable in skin sites far from the primary infection site. Resident memory $\mathrm{T}$ cells do not rely on residual parasites, produce IFN- $\gamma$ upon re-stimulation and contribute to the rapid recruitment of cells back into the infection site, early after reinfection (Glennie et al., 2015). These early recruited $\mathrm{T}$ cells could be $\mathrm{CD} 44^{+} / \mathrm{Ly} \mathrm{C}^{+} \mathrm{T}$ - effector cells, however, this needs to be further addressed. Furthermore, primary Leishmania infection resolution is undoubtedly $\mathrm{CD} 8^{+} \mathrm{T}$ cell-dependent with respect to natural infection features. After complete resolution, $\mathrm{CD}^{+}$memory $\mathrm{T}$ cells are responsible for secondary infection control in addition to CD4 ${ }^{+} \mathrm{T}$ cells (Muller, 1992). These cells promote long-lasting protection, which is compromised in the absence of activated CD8 ${ }^{+} \mathrm{T}$ cells (Gurunathan et al., 2000; Mendez et al., 2001). Some controversial data has recently raised concern about the role of these cells in secondary infection after low dose or high dose challenge, but undoubtedly confirm that $\mathrm{CD}^{+} \mathrm{T}$ cells contribute to optimal primary immunity and establishment of successful memory response (Okwor et al., 2014). Our recently published data indicates that $\mathrm{CD}^{+} \mathrm{T}$ cells are very important in protection induced by a polytope DNA construct expressing individual MHC-I restricted peptides in $\mathrm{Balb} / \mathrm{c}$ mice and that $\mathrm{CD} 8^{+} \mathrm{T}$ cell depletion clearly abrogates $\mathrm{Th} 1$ response deviation (Zandieh et al., 2015).

To conclude, despite all the unanswered questions about immunity to leishmaniasis, multifunctional $\mathrm{CD} 4{ }^{+}$and $\mathrm{CD}^{+}$ $\mathrm{T}$ cells are undoubtedly essential in a pro-inflammatory Th1 environment to control the disease. Thus far, all the vaccine approaches have focused on $\mathrm{CD} 4^{+} \mathrm{T}$ cell stimulations, neglecting the important $\mathrm{CD}^{+} \mathrm{T}$ cells. However, new advancements during the post-genomics era will improve vaccine design through multiple online immunoinformatics tools to mine whole genomes for potential candidates with both $\mathrm{CD} 4^{+}$and $\mathrm{CD} 8^{+}$ 
T cell-stimulating capabilities, in addition to new strategies. Inborn differences within Leishmania species, the pertinent disease and a good understanding of the immunopathological mechanisms displayed by $\mathrm{CD} 4^{+}$and $\mathrm{CD} 8^{+} \mathrm{T}$ cells must be kept in mind when planning new therapeutic and vaccine strategies in human leishmaniasis. Recently published data reinforce the vaccine researchers to reconsider two main facts in Leishmania vaccine: the chronic parasitic infection after successful healing of primary infection (which has recently highlighted novel aspects of immunity to reinfection mediated by $\mathrm{CD}^{+} \mathrm{T}$ cells) and sandfly challenge infection instead of needle challenge.

\section{CONVENTIONAL AND REVERSE VACCINOLOGY CONCEPTS}

Historically, vaccination was introduced through the elegant experiment that was performed by Edward Jenner in 1801 (Henderson, 1997). However, Louis Pasteur was the one who established the principles of vaccination as "isolation, inactivation and inoculation" after the discovery of the causative agents of diseases. These rules provided a basis for conventional vaccinology and led to several effective vaccine developments against multiple pathogens. The in vitro killing or attenuation of the whole pathogen by physical or chemical methods and the isolation and characterization of potential immunogenic subunits of the cultured pathogen are the primary concerns of conventional approaches (Rappuoli, 2007). Fortunately, killed, live attenuated or even pathogen subunits have successfully lowered the incidence of many infectious diseases and have increased the average human life expectancy (André, 2003; Moriel et al., 2008). However, decades of experiments have shown that vaccine-prone pathogens are among those that actually do not undergo antigenic variation and are effectively cleared by antibody responses. By contrast, diseases that are caused by pathogens such as HIV and Influenza with numerous variants and those that demand cellular immune responses to be controlled, such as leishmaniasis, malaria and tuberculosis, still await effective vaccines (Rappuoli and Aderem, 2011).

In 1995, the complete genome of Haemophilus influenzae was published as the first entire genome sequence. Since then, 1000s of genomes have been sequenced and made available in data banks. The huge amount of data that is available from sequenced genomes could not be manually integrated into the desired data sets. The concomitant advancements in computer-based algorithms and "omics" such as proteomics, transcriptomics, immunomics, functional genomics and in systems biology have helped to extract the data from the genome and to integrate them into vaccine concepts (Rinaudo et al., 2009; Seib et al., 2009). This approach is called "reverse vaccinology" because it begins at the genome sequence (and not at the cell) to select potential vaccine candidates using computer-based high throughput screening (De Groot and Rappuoli, 2004). Reverse vaccinology has the potential to extend the number of subunit candidates of a pathogen from none or a few that were identified by conventional vaccinology to a genome-wide scale, saving time and energy. If the pathogen of interest is successfully controlled by humoral immune responses and neutralizing antibodies, the genome-wide screening could be further confined to the potential surface-exposed or secretory antigens. Otherwise, the genome-wide antigenic capacity is open to surveys for $\mathrm{T}$ cell epitopes as cellular immune response inducers.

\section{CURRENT STATUS OF Leishmania VACCINES: WHAT WE HAVE GAINED FROM CONVENTIONAL VACCINOLOGY}

Leishmanization has made an important contribution to Leishmania vaccine history. Exudates from active lesions containing live infectious parasites were directly inoculated into naive individuals (Nadim et al., 1983). Although it could be potentially protective by polarizing Th1 immune responses, leishmanization was discontinued because of serious concerns about its safety and standardization, problems that still remain to be resolved (Amini, 1991; Dunning, 2009). To follow Pasteur's rule, killed Leishmania promastigotes entered the Leishmania vaccine field in 1940. Since then, different approaches have been examined to compensate the low immunogenicity of killed parasites such as BCG (Momeni et al., 1999) or CpG oligonucleotide (Heravi Shargh et al., 2012) supplementation. However, inconsistent clinical outcomes have raised serious questions about the protection potential in humans (Noazin et al., 2008).

Live parasites with attenuated pathogenicity were then developed to cover the inborn limitations of live infectious vaccination and killed vaccines. Live attenuated vaccines expose the recipient to the entire antigenic capacity of Leishmania and "pathogen-associated molecular patterns" that are necessary for the proper activation of immune responses but ideally lack pathogenicity potential (Silvestre et al., 2008). Conventional attenuation is achieved by exposure to chemicals, consecutive cultures or gamma irradiation (Alexander, 1982), all of which give rise to non-pathogenic strains with genetically undefined random mutations. Instead, targeted gene manipulation further facilitated the specific manipulation of virulence-related genes and resulted in many successful attenuated strains (Selvapandiyan et al., 2009; Dey et al., 2013). Although it is promising, the major concern about live attenuated vaccines is the risk of reversion to the wild type strain from compensatory gene expression in Leishmania (Spath et al., 2004). Therefore, human clinical trials still remain challenging. It is noteworthy to mention the importance of newly introduced nonpathogenic Leishmania species such as Leishmania tarentolae, which highly resemble pathogenic strains but lack virulence genes (Raymond et al., 2012). These species strongly stimulate Th1-type responses, and they are promising surrogates for live vaccines (Saljoughian et al., 2014).

To lower the safety risks of whole pathogen vaccines, subcellular components have attracted attention for generating subunit vaccines. Conventionally, subunits are identified by serological, biochemical, microbiological and molecular genetics approaches (Raju and Rao, 2010). After decades of investigation, almost 30 different protein subunits of Leishmania are labor intensively isolated, characterized and introduced as vaccine 
candidates. These subunits are primarily identified on the basis of their abundance (gp63) (Etges et al., 1985), by screening expression libraries with sera from infected animals (TSA) (Webb et al., 1998), by expressed sequence tag analyses of cDNA libraries (LeIF) (Almeida et al., 2004), by screening parasite fractions from sera obtained from infected humans (CPs) (Rafati et al., 2001) and by differential cloning (A2) (Charest and Matlashewski, 1994). Because resistance against Leishmania infection requires Th1-type cellular immunity and because the proteins evidently stimulate weak or no cellular responses, the characterized protein subunits have been formulated in various iterations. Many innovative adjuvants (Raman et al., 2012) including CpG oligonucleotides (Ramírez et al., 2013), delivery systems (Doroud and Rafati, 2012) including liposomes (Colhone et al., 2015), a combination of adjuvants and a delivery system (Das and Ali, 2014), DNA constructs (Taheri and Rafati, 2013), stand-alone versions (Iborra et al., 2004) or those with delivery systems (Doroud et al., 2011) and vectored vaccines (Griffiths and Khader, 2014) including non-pathogenic L. tarentolae (Zahedifard et al., 2014) have been extensively investigated to compensate for the low efficiency of the proteins. However, despite the satisfactory protection levels in animal models, no effective human vaccine has entered the market yet. Multi-subunit vaccines have been shown to be more promising (Rafati et al., 2005, 2006), and the only vaccine formulation that is now in human clinical trials is Leish-F. This vaccine is a tri-fusion protein composed of TSA, LmSTI1 and LeIF, which are three well-conserved Leishmania proteins, and this vaccine has successfully protected mice, hamsters, and rhesus macaques in MPL-SE formulation (Campos-Neto et al., 2001; Skeiky et al., 2002). Together, several clinical trials have shown that the LEISH-F1 + MPL-SE vaccine is safe and immunogenic in patients with LCL and MCL (LlanosCuentas et al., 2010; Chakravarty et al., 2011). LEISH-F1 was formulated with GLA-SE, a new promising adjuvant, and it has shown even better responses in comparison with those of MPL-SE (Coler et al., 2015). Other poly-protein vaccine formulation with diverse subunit candidates including CPACPB-A2 (Saljoughian et al., 2013; Shahbazi et al., 2015b) and A2-Kmp11-CPB-SMT (KSAC) (Goto et al., 2011), have also shown promising results in experimental models and even dogs (Shahbazi et al., 2015a).

Despite all successful protections conferred by different subunit vaccine formulations, unraveling the role of vector's saliva in Leishmania infection (Gomes et al., 2012) raised a big concern: vector transmission of Leishmania abrogates vaccine-induced protection (Peters et al., 2009, 2012). Sandfly challenge massively recruits neutrophils to the infection site and strongly promotes "Trojan Horse" pathway but needle challenge is less reactive in respect to neutrophil recruitment and this might basically explain vaccination failure after sandfly challenge (Peters et al., 2009). To resolve this, several groups have used salivary related immunostimulatory proteins like SP15 as vaccine and have challenged either with needle and pertinent salivary gland homogenate/SGH (Katebi et al., 2015) or infected sandfly instead (Oliveira et al., 2015). Together their concept has shown promising in protection against Leishmania challenge. Respecting these results, combining effective vaccine candidates (could be mined out of whole genome sequence) and salivary proteins seems a better idea to further improve subunit vaccine approach (Kamhawi et al., 2014a; Zahedifard et al., 2014) which less complexes with safety concerns than the leishmanization or the live attenuated vaccines.

\section{HOW CAN REVERSE VACCINOLOGY AMELIORATE THE CURRENT STATUS OF THE Leishmania VACCINE?}

Since the completion of the whole genome sequence of Leishmania major (Friedline reference strain) in 2005, approximately 8298 protein coding genes were identified on approximately 33 mega-base pair genomes (Ivens et al., 2005). This approach has attracted interest in relation to finding new vaccine candidates by reverse methods (Stober et al., 2006). In recent years, remarkable advancements in immunoinformatics science have improved potential immunogenic epitope selections from the genomes of various pathogens (De Groot et al., 2002; Tang et al., 2011). This in silico peptide mapping approach is the basis for "fishing antigens using epitopes as bait" (He et al., 2010) because it identifies highly ranked proteins with both $\mathrm{CD} 4^{+}$ and $\mathrm{CD}^{+}{ }^{+} \mathrm{T}$ cell-stimulating potential, thus helping to extend vaccine candidates (Paape and Aebischer, 2011; Aebischer, 2014; Singh et al., 2015). Furthermore, If we believe the concept in which "the most efficient immune response to some pathogens is derived from a number of different $\mathrm{T}$ cells that respond to an ensemble of pathogen-derived short peptides called epitopes (De Groot et al., 2002)," then epitope mapping can be further used to design "poly-epitopes" or "polytopes" as vaccines. Polytope ensembles are preferable surrogates for the pathogen body (always linked to pathogenicity reversion risk) because peptide epitopes from one potential protein, or the different proteins of one strain, or conserved proteins from different strains of a species could be easily assembled together. HLA-transgenic mice are now available from different companies to evaluate both epitope immunogenicity and polytope vaccine efficiency. Because they carry human HLA as their MHC background, these models are perfect surrogates for any other mice model. They help to evaluate not only the in vivo immunogenicity of predicted peptides that bind to human HLA (Seyed et al., 2014) but also the protective efficacy of polytopic constructs that encode multiple human-HLA-restricted epitopes. The latter is still missing in Leishmaniasis.

Reverse vaccinology could also make the live attenuated vaccine dream come true. A pathogen's genome encodes thousands of proteins, and few are crucial for pathogenesis and virulence. The essential genes in Leishmania that are involved in promastigote to amastigote differentiation, amastigote survival and immune system evasion are apparently related to virulence. This complicates random gene attenuation by physical or chemical methods. Forward genetics identifies virulence-related genes beginning from a mutant or variant phenotype for further targeted gene manipulation (Beverley, 2003). This approach is a labor-intensive task for live attenuated parasite generation, especially in complex organisms such as Leishmania. 
By contrast, reverse vaccinology through comparative or subtractive genomics will cut the time to targeted live attenuated vaccine development by many folds since genomic sequences of pathogenic and non-pathogenic strains are now available. Different computational tools make it possible to find crucial gene/s through comparative analyses between different pathogenic strains (to distinguish species-specific genes and the core genome) (Peacock et al., 2007) and a subtractive analyses with non-pathogenic strains such as L. tarentolae (to find relevant virulence factors) (Raymond et al., 2012). These types of analyses allow for the identification of genes and proteins that are very specific for virulence (in addition, the prediction algorithms and in silico tools help to predict protein interactions in biological systems between the host and the invaded cell, which further ameliorates pathogen-specific drug screening) (Ali et al., 2013). Fortunately, most Leishmania strains are transfectable and will tolerate many genetic manipulations. Together with advanced transfection techniques, the targeted manipulation of pathogenic strains at actual virulence-related genes might further guarantee reversion failure.

\section{FISHING NEW VACCINE CANDIDATES FROM THE GENOME BY USING EPITOPES AS BAIT}

Epitopes are the smallest immune-stimulatory units of a protein that are presented by major-histocompatibility complexes. MHC molecules are among the most heterogeneous gene families in humans. Each allele specifically accepts peptides bearing compatible binding motifs with an HLA binding groove. The term "Epitope Mapping" is used to identify epitopes from a protein that bind MHC molecules with proper affinity and stimulate $\mathrm{T}$ cell (or $\mathrm{B}$ cell) responses. In general, MHC binding is a crucial determinant for $\mathrm{T}$ cell activation, but for $\mathrm{CD}^{+} \mathrm{T}$ cells, factors other than MHC binding are also important. Intracellular proteins are chopped into peptides by proteasomal enzymatic cleavage and are destined for the MHC-I compartment (via TAP molecules) in the endoplasmic reticulum. Classical approaches select immunogenic epitopes within pools of synthetic overlapping peptides (usually 15-mers) that stimulate $\mathrm{T}$ cell clones in vitro and/or in vivo (Basu et al., 2007; Das et al., 2014). The time and energy that are consumed this way because of the large number of peptides that must be evaluated could be saved by immunoinformatics. Immunoinformatics is the part of bioinformatics science that is concerned with the computational prediction of $\mathrm{T}$ cell (and $\mathrm{B}$ cell) epitopes from proteins (Tomar and De, 2010) and is powered to reduce the number of peptides that are valuable for further study. All we need are mathematical algorithms that are capable of predicting MHC binding, presentation and TCR activation. Both the sequence and structure of proteins have been considered during the development of predictive algorithms (Liao and Arthur, 2011; Resende et al., 2012). Those that are based on sequences include "motif-based methods," "quantitative matrices" and "machine learning methods."
Motif-based methods are relatively simple approaches that look for allele-specific binding motifs (Falk et al., 1991). Each allele has anchor positions that best fit with the anchor residues of a peptide. Thus, a peptide with preferable anchor residues is expected to be a binder. However, the identification of potential binders without preferred anchor residues has raised the possibility that not only the anchor but also the neighboring positions play considerable roles in $\mathrm{MHC}$-peptide interaction. This line of reasoning led to matrix-based methods, although motif-based methods are still used. In any given matrix, each amino acid at each specific position has a defined score. The final score of each peptide sequence is then the sum or multiplication of individual scores used by the algorithm. All peptides derived from a protein with a given length are then ranked from the top-scored peptides to the last one. SYFPEITHI is among the very well-known matrix-based methods that are extensively used for in silico peptide prediction (Rammensee et al., 1999; Dikhit et al., 2015; Ip et al., 2015). Because epitopes that are extracted from MHC molecules are the primary contributors to matrix design, these methods are not actually able to discriminate between binders and non-binders. To find true positive epitopes, $10 \%$ of the top ranked peptides should be further evaluated in vitro and/or in vivo. However, matrixbased methods underestimate the impact of neighboring amino acids on the binding affinity of an amino acid at each position (non-linearity). Machine learning methods instead fix these drawbacks. Artificial Neural Networks (ANN), Hidden Markov Models (HMM), and Support Vector Machines (SVM) not only efficiently classify the peptide contents of a protein into binders and non-binders with high positive predictive values but also consider non-linearity using mathematical algorithms (Luo et al., 2015). Finally, structure-based algorithms predict epitopes with 3D-structural information from MHC molecules and peptides. According to in silico docking, peptides with a binding affinity for a given MHC are selected (Patronov and Doytchinova, 2013). Inborn limitations underlying motif-based and structural-based methods have made matrix-based and machine learning methods the first choices for in silico predictions (Shipo Wu et al., 2012) with multiple open access tools on the World Wide Web. Initially, users might become confused by the large amount of available software. However, it is better to keep in mind that the more algorithms that are used, the better the results (Yu et al., 2002).

Different groups have already started to mine the Leishmania genome for new vaccine candidates by using peptide maps of mouse MHC-I (Guerfali et al., 2009; Herrera-Najera et al., 2009) or human HLA-I (Schroeder and Aebischer, 2011; John et al., 2012; Singh et al., 2015) molecules. MHC-II epitope prediction is more difficult and less sensitive than MHC-I prediction. Therefore, there is still a lack of data about epitopes from Leishmania species in mouse or human HLA-class-II molecules to describe new potential protein candidates, and we need to collect this information. The primary priority in the Leishmania parasite is to focus on amastigote-specific proteins. Thus, proteomics or phospho-proteomics data from the amastigote stage will restrict whole genome screening to the amastigotespecific proteome (Paape and Aebischer, 2011). For CD8 ${ }^{+}$T cell epitope selection, some prefer to consider surface or secreted 
proteins (Naouar et al., 2016), but this consideration may cause potential epitopes from intracellular proteins to be overlooked. Recently published data show that epitopes from LPG-3 and LmSTI-1 as intra-cellular molecules can recall $\mathrm{CD}^{+} \mathrm{T}$ cell responses from CL-recovered HLA-A2 ${ }^{+}$individuals (Seyed et al., 2011). Therefore, genome-wide screening for novel antigens irrespective of sub-cellular localization could further extend the vaccine candidate list for the Leishmania parasite.

\section{POLY-EPITOPE CONSTRUCT DESIGN BASED ON GENOME-DERIVED EPITOPES}

Multiple formulations are recommended for polytope ensembles. One is a direct inoculation of epitope mixtures. Because single peptides are weak immune-stimulators per se, robust adjuvanting systems such as cytokines, Toll-Like-Receptor ligands, CpG oligo-nucleotides or dendritic cell-based systems are needed. In addition, these peptides are at risk of degradation by endopeptidase or exopeptidase activity at the injection site and in circulation. Thus, putting them together in long peptide assemblies reduces the degradation risk but makes the synthesis and production rather difficult (Lu et al., 2004; Slingluff, 2011). Alternatively, self-adjuvanted nucleic acid constructs with remarkable potential to promote both $\mathrm{CD} 4^{+}$and $\mathrm{CD} 8^{+} \mathrm{T}$ cell responses are more attractive than peptide assemblies (Cho and Celis, 2012). Moreover, DNA prime-peptide boost (heterologous) regimens further potentiate T-cell responses (Moise et al., 2011). Polytope DNA constructs should be rationally designed by focusing on some critical points such as minimal junctional peptides, optimal proteasomal degradation for $\mathrm{CD}^{+} \mathrm{T}$ cell epitopes and secretory pathway guidance for $\mathrm{CD}^{+} \mathrm{T}$ cell epitopes.

Junctional peptides are inevitable in a "string of beads" in which $\mathrm{T}$ cell epitopes are in tandem. If dominant, these peptides will affect the immune response. To avoid junctional peptides, spacers such as AAA (Jafarpour et al., 2014), AAY (Huebener et al., 2008), K (Li et al., 2005) and AD (Bazhan et al., 2010) for $\mathrm{CD}^{+} \mathrm{T}$ cell epitopes and GPGPG for $\mathrm{CD} 4^{+} \mathrm{T}$ cell epitopes (Moise et al., 2011) are recommended. Spacers starting with " $A$ " are more frequently used with respect to the "P1 premise." Accordingly, the chance of proteasomal cleavage increases once the $\mathrm{P} 1$ amino acid next to the C-terminal peptide is alanine (Neisig et al., 1995). It is now possible to compare different possibilities for epitope arrangements with or without spacers by immunoinformatics, which can efficiently predict the cleavage sites on the polytope sequence (Seyed et al., 2014). Another important note is that endogenously synthesized proteins that are destined for proteasomal degradation are ubiquitinated only if they carry degradation signals (Mogk et al., 2007). Artificial proteins such as polytopes without internal signals are longlived molecules with long half-lives before degradation. This tendency could be compensated by ubiquitination with a single ubiquitin molecule (76 amino acid long) that is covalently attached to a polypeptide chain. Each molecule recruits more molecules and consequently makes a poly-ubiquitinated polytope
(Sharma and Madhubala, 2009). Alternatively, the N-terminal signal peptide could be used instead of ubiquitination (Eslami et al., 2012). Although the $\mathrm{CD}^{+} \mathrm{T}$ cell response has been shown to be essential in Leishmania clearance, polytopes aimed at $\mathrm{CD}^{+} \mathrm{T}$ cell induction remain to be addressed with regards to Leishmania infection. Our group has recently shown that a rationally designed DNA construct that encodes multiple $\mathrm{CD}^{+}$ $\mathrm{T}$ cell epitopes from Leishmania proteins effectively stimulate cytotoxic $\mathrm{T}$ cells in both Balb/c and HLA transgenic C57BL/6 experimental models (Seyed et al., 2014). Others have focused on human HLA-I or -II epitope prediction from well-known vaccine candidates such as CPs, gp63, LeIF, LmSTI-1, KmP11 and LPG-3 by using an immunoinformatics approach for future vaccine design (Saffari and Mohabatkar, 2009; Seyed et al., 2011; Elfaki et al., 2012; Rezvan, 2013; Agallou et al., 2014).

In addition to ubiquitination and optimal cleavage, $\mathrm{T}$ helpers are also a primary concern during the rational design of polytopes. $\mathrm{T}$ Helper-inducing peptides are necessary for $\mathrm{CD}^{+} \mathrm{T}$ cell priming. PADRE (Cong et al., 2012) and Tetanus Toxoid-derived peptides are extensively used for this purpose. These peptides are applicable to both mouse and human studies, and they induce Th1-type responses whenever permitted. In any case, $\mathrm{CD} 4^{+} \mathrm{T}$ cell-inducing epitopes should be destined for the excretory pathway, to enter the MHC class-II compartment. Signal peptides are efficient at this responsibility.

The HLA heterogeneity of human populations is still a remaining obstacle to surmount. Promiscuous epitopes presented by HLA super-types are a solution. Super-types are allelic groups with close but not exact binding motifs or "supermotifs" that bind a group of peptides with more or less comparable affinities. Nine different supertypes have already been characterized, and it is postulated that 3 out of 9, including A2, A3 and B7, cover more than $90 \%$ of the global population. The remaining percentage should be covered by population-specific alleles (Reche and Reinherz, 2007). Predicting promiscuous epitopes is an easy task now and immunoinformatics fulfills this job with algorithms such as NetMHCpan and NetMHCpanII for MHC-I and MHC-II, respectively. Although we are still far from an ideal polytope vaccine for human population, some researchers have studied the protective potential of epitope vaccines against Leishmania infectious challenges in experimental models (Spitzer et al., 1999; Sachdeva et al., 2009; Agallou et al., 2011; Kedzierska et al., 2012). Recently published data provide the proof of concept for T cell-based Leishmania vaccines. Das et al. (2014) have prepared DNA constructs that are enriched with $\mathrm{CD}^{+}{ }^{+}$and $\mathrm{CD}^{+}{ }^{+} \mathrm{T}$ cell stimulatory segments of four different proteins to minimize the HLA effect. The vaccine has been shown to be protective in a rodent model of VL (Das et al., 2014), and it is a candidate for human clinical trials (Riede et al., 2015). The hallmark of LEISHDNAVAX is that the vaccine antigens were tested with $\mathrm{T}$ cells from leishmaniasis-recovered individuals, and they have been shown to be immunogenic in genetically diverse human populations, starting from humans and ending in a human vaccine (Kamhawi et al., 2014b). 
Not only can polytopic constructs serve as prophylactic vaccines, but they are also a promising approach for immunotherapy. Recently, Teh-Poot et al. (2015) successfully evaluated the immunotherapeutic potential of a mixture of 10 peptides in Trypanosoma cruzi-infected mice. The therapeutic vaccine controlled the resulting parasitemia, cardiac tissue inflammation and parasite burden (Teh-Poot et al., 2015).

\section{HLA TRANSGENIC MICE PAVE THE PATHWAY "FROM HUMAN TO HUMAN"}

Mouse models are very well-known experimental models in Leishmania research. However, subtle differences in peptide presentations by mouse MHC or human HLA systems might be one possible explanation for the failure of protective vaccines in human trials. To fill this gap between experimental models and human applications, new experimental models were generated to express human HLA molecules in mice (Pascolo, 2005). In the preliminary models, the immune response was more mouse MHC and less human HLA-restricted. However, advancements in transgenesis and gene manipulation techniques further facilitated mice MHC knockout by replacing the gene with a complete human HLA sequence. In these transgenic animals, the human HLA allele is the only source of T-cell training in the thymus; thus, they are invaluable models for bridging the gap between laboratory and human field studies, especially for peptide prediction and polytope vaccine development.

Animals that express either human HLA class-I or -II or both class-I and II, are now available from different companies. These pre-clinical models have revolutionized studies from human in silico approaches to human in vivo experiments before being moved to clinical trials, that is to say, from humans to humans (Kotturi et al., 2009). Many investigators have harnessed the model's potential for evaluating human-derived epitopebased vaccine efficacy both in tumor cell challenges (Dosset et al., 2012; Ding et al., 2013) and different infections such as Poxvirus (Moise et al., 2011), Toxoplasma gondii (Cong et al., 2012), Mycobacterium tuberculosis (Geluk et al., 2012) and Plasmodium falciparum (Mahajan et al., 2010). Our group has also recently shown the immunogenicity of a polytope DNA

\section{REFERENCES}

Aebischer, T. (2014). Leishmania spp. proteome data sets: a comprehensive resource for vaccine development to target visceral leishmaniasis. Front. Immunol. 5:260. doi: 10.3389/fimmu.2014.00260

Agallou, M., Athanasiou, E., Koutsoni, O., Dotsika, E., and Karagouni, E. (2014). Experimental validation of multi-epitope peptides including promising MHC class I-and II-restricted epitopes of four known Leishmania infantum proteins. Front. Immunol. 5:268. doi: 10.3389/fimmu.2014.00268

Agallou, M., Margaroni, M., and Karagouni, E. (2011). Cellular vaccination with bone marrow-derived dendritic cells pulsed with a peptide of Leishmania infantum KMP-11 and CpG oligonucleotides induces protection in a murine model of visceral leishmaniasis. Vaccine 29, 5053-5064. doi: 10.1016/j.vaccine.2011.04.089

Alexander, J. (1982). A radioattenuated Leishmania major vaccine markedly increases the resistance of CBA mice to subsequent infection with Leishmania construct that encodes multiple $\mathrm{CD}^{+}{ }^{+} \mathrm{T}$ cell-stimulating peptides in HLA-A2 transgenic mice as the first report in Leishmania (Seyed et al., 2014). Previously, Rezvan et al. (2012) showed the immunogenicity of HLA-I and HLA-II (Rezvan, 2013)-restricted peptides from Leishmania-gp63 in relevant pre-clinical models. However, data to support the protective efficacy of epitope vaccines against Leishmania are still missing.

\section{CONCLUDING REMARK}

Today there are almost 30 different characterized proteins, out of at least 8000 proteins encoded in the parasite genome, for vaccine studies. This substantiates further characterization of new protein candidates both as virulence factors to generate more reliable live attenuated parasites and also as members of more effective multi-subunit vaccines to obtain better vaccine modalities. This could be achieved from mining the full sequenced genome of the Leishmania species now available. Hopefully massive data extrapolated from the genome will further revolutionize the future of vaccine design and drug development by unraveling the mysteries around the biology of the parasite.

\section{AUTHOR CONTRIBUTIONS}

All authors listed, have made substantial, direct and intellectual contribution to the work, and approved it for publication.

\section{FUNDING}

Authors of the manuscript wish to acknowledge Pasteur Institute of Iran and National Science Foundation of Iran (grant no. 87020176 and 91053539 to SR) for funding this research.

\section{ACKNOWLEDGMENT}

We also wish to thank INSERM U1098 Besançon, France for their support and collaboration.

mexicana mexicana. Trans. R. Soc. Trop. Med. Hyg. 76, 646-649. doi: 10.1016/0035-9203(82)90232-2

Ali, A., Soares, S., Barbosa, E., Santos, A., and Barh, D. (2013). Microbial comparative genomics: an overview of tools and insights into the genus Corynebacterium. J. Bacteriol. Parasitol. 4, 167. doi: 10.4172/2155-9597.1000167

Almeida, R., Gilmartin, B. J., Mccann, S. H., Norrish, A., Ivens, A. C., Lawson, D., et al. (2004). Expression profiling of the Leishmania life cycle: cDNA arrays identify developmentally regulated genes present but not annotated in the genome. Mol. Biochem. Parasitol. 136, 87-100. doi: 10.1016/j.molbiopara.2004.03.004

Alvar, J., Croft, S. L., Kaye, P., Khamesipour, A., Sundar, S., and Reed, S. G. (2013). Case study for a vaccine against leishmaniasis. Vaccine 31(Suppl. 2), B244-B249. doi: 10.1016/j.vaccine.2012.11.080

Alvar, J., Vélez, I. D., Bern, C., Herrero, M., Desjeux, P., Cano, J., et al. (2012). Leishmaniasis worldwide and global estimates of its incidence. PLoS ONE 7:e35671. doi: 10.1371/journal.pone.0035671 
Amini, H. (1991). Cutaneous lesions with very long duration as a complication of leishmanization. Iran. J. Public Health 20, 43-50.

Anderson, C. F., Oukka, M., Kuchroo, V. J., and Sacks, D. (2007). CD4(+)CD25(-)Foxp3(-) Th1 cells are the source of IL-10-mediated immune suppression in chronic cutaneous leishmaniasis. J. Exp. Med. 204, 285-297. doi: 10.1084/jem.20061886

André, F. E. (2003). Vaccinology: past achievements, present roadblocks and future promises. Vaccine 21, 593-595. doi: 10.1016/S0264-410X(02)00702-8

Basu, R., Roy, S., and Walden, P. (2007). HLA class I-restricted T cell epitopes of the kinetoplastid membrane protein-11 presented by Leishmania donovani-infected human macrophages. J. Infect. Dis. 195, 1373-1380. doi: $10.1086 / 513439$

Bazhan, S., Karpenko, L., Ilyicheva, T., Belavin, P., Seregin, S., Danilyuk, N., et al. (2010). Rational design based synthetic polyepitope DNA vaccine for eliciting HIV-specific CD8+ T cell responses. Mol. Immunol. 47, 1507-1515. doi: 10.1016/j.molimm.2010.01.020

Belkaid, Y., Hoffmann, K. F., Mendez, S., Kamhawi, S., Udey, M. C., Wynn, T. A., et al. (2001). The role of interleukin (IL)-10 in the persistence of Leishmania major in the skin after healing and the therapeutic potential of anti-IL-10 receptor antibody for sterile cure. J. Exp. Med. 194, 1497-1506. doi: 10.1084/jem.194.10.1497

Belkaid, Y., Mendez, S., Lira, R., Kadambi, N., Milon, G., and Sacks, D. (2000). A natural model of Leishmania major infection reveals a prolonged "silent" phase of parasite amplification in the skin before the onset of lesion formation and immunity. J. Immunol. 165, 969-977. doi: 10.4049/jimmunol.165.2.969

Belkaid, Y., Piccirillo, C., Mendez, S., Shevach, E., Sacks, D., Suvas, S., et al. (2002a). $\mathrm{CD} 4+\mathrm{CD} 25+$ regulatory $\mathrm{T}$ cells control Leishmania major persistence and immunity. Nature 420, 502-507. doi: 10.1038/nature01152

Belkaid, Y., Von Stebut, E., Mendez, S., Lira, R., Caler, E., Bertholet, S., et al. (2002b). CD8+ T cells are required for primary immunity in C57BL/6 mice following low-dose, intradermal challenge with Leishmania major. J. Immunol. 168, 3992-4000. doi: 10.4049/jimmunol.168.8.3992

Beverley, S. M. (2003). Genetic and Genomic Approaches to the Analysis of Leishmania Virulence. New York, NY: Academic Press.

Bunn, P. T., Stanley, A. C., De Labastida Rivera, F., Mulherin, A., Sheel, M., Alexander, C. E., et al. (2014). Tissue requirements for establishing long-term CD4+ T cell-mediated immunity following Leishmania donovani infection. J. Immunol. 192, 3709-3718. doi: 10.4049/jimmunol.1300768

Campanelli, A. P., Roselino, A. M., Cavassani, K. A., Pereira, M. S., Mortara, R. A., Brodskyn, C. I., et al. (2006). CD4+CD25+ T cells in skin lesions of patients with cutaneous leishmaniasis exhibit phenotypic and functional characteristics of natural regulatory T cells. J. Infect. Dis. 193, 1313-1322. doi: 10.1086/502980

Campos-Neto, A., Porrozzi, R., Greeson, K., Coler, R. N., Webb, J. R., Seiky, Y. A., et al. (2001). Protection against cutaneous leishmaniasis induced by recombinant antigens in murine and nonhuman primate models of the human disease. Infect. Immun. 69, 4103-4108. doi: 10.1128/IAI.69.6.4103-4108.2001

Chakravarty, J., Kumar, S., Trivedi, S., Rai, V. K., Singh, A., Ashman, J. A., et al. (2011). A clinical trial to evaluate the safety and immunogenicity of the LEISHF1+ MPL-SE vaccine for use in the prevention of visceral leishmaniasis. Vaccine 29, 3531-3537. doi: 10.1016/j.vaccine.2011.02.096

Chappuis, F., Sundar, S., Hailu, A., Ghalib, H., Rijal, S., Peeling, R. W., et al. (2007). Visceral leishmaniasis: what are the needs for diagnosis, treatment and control? Nat. Rev. Microbiol. 5, 873-882. doi: 10.1038/nrmicro1748

Charest, H., and Matlashewski, G. (1994). Developmental gene expression in Leishmania donovani: differential cloning and analysis of an amastigote-stagespecific gene. Mol. Cell. Biol. 14, 2975-2984. doi: 10.1128/MCB.14.5.2975

Cho, H. I., and Celis, E. (2012). Design of immunogenic and effective multi-epitope DNA vaccines for melanoma. Cancer Immunol. Immunother. 61, 343-351. doi: 10.1007/s00262-011-1110-7

Coler, R. N., Duthie, M. S., Hofmeyer, K. A., Guderian, J., Jayashankar, L., Vergara, J., et al. (2015). From mouse to man: safety, immunogenicity and efficacy of a candidate leishmaniasis vaccine LEISH-F3+GLA-SE. Clin. Transl. Immunol. 4:e35. doi: 10.1038/cti.2015.6

Colhone, M. C., Silva-Jardim, I., Stabeli, R. G., and Ciancaglini, P. (2015). Nanobiotechnologic approach to a promising vaccine prototype for immunisation against leishmaniasis: a fast and effective method to incorporate GPI-anchored proteins of Leishmania amazonensis into liposomes. J. Microencapsul. 32, 143-150. doi: 10.3109/02652048.2014.958203
Cong, H., Mui, E. J., Witola, W. H., Sidney, J., Alexander, J., Sette, A., et al. (2012). Toxoplasma gondii HLA-B*0702-restricted GRA7(20-28) peptide with adjuvants and a universal helper $\mathrm{T}$ cell epitope elicits $\mathrm{CD} 8(+) \mathrm{T}$ cells producing interferon-gamma and reduces parasite burden in HLA-B*0702 mice. Hum. Immunol. 73, 1-10. doi: 10.1016/j.humimm.2011.10.006

Convit, J., Kerdel-Vegas, F., and Gordon, B. (1962). Disseminated anergic cutaneous leishmaniasis. Br. J. Dermatol. 74, 132-135. doi: 10.1111/j.13652133.1962.tb13475.x

Courret, N., Lang, T., Milon, G., and Antoine, J. C. (2003). Intradermal inoculations of low doses of Leishmania major and Leishmania amazonensis metacyclic promastigotes induce different immunoparasitic processes and status of protection in BALB/c mice. Int. J. Parasitol. 33, 1373-1383. doi: 10.1016/S0020-7519(03)00179-6

Croft, S. L., and Olliaro, P. (2011). Leishmaniasis chemotherapy-challenges and opportunities. Clin. Microbiol. Infect. 17, 1478-1483. doi: 10.1111/j.14690691.2011.03630.x

Darrah, P. A., Patel, D. T., De Luca, P. M., Lindsay, R. W., Davey, D. F., Flynn, B. J., et al. (2007). Multifunctional TH1 cells define a correlate of vaccinemediated protection against Leishmania major. Nat. Med. 13, 843-850. doi: $10.1038 / \mathrm{nm} 1592$

Das, A., and Ali, N. (2014). Combining cationic liposomal delivery with MPLTDM for cysteine protease cocktail vaccination against Leishmania donovani: evidence for antigen synergy and protection. PLoS Negl. Trop. Dis. 8:e3091. doi: 10.1371/journal.pntd.0003091

Das, S., Freier, A., Boussoffara, T., Oswald, D., Losch, F. O., Selka, M., et al. (2014). Modular multiantigen $\mathrm{T}$ cell epitope-enriched DNA vaccine against human leishmaniasis. Sci. Transl. Med. 6, 234-256. doi: 10.1126/scitranslmed.3008222

De Groot, A. S., and Rappuoli, R. (2004). Genome-derived vaccines. Expert Rev. Vaccines 3, 59-76. doi: 10.1586/14760584.3.1.59

De Groot, A. S., Sbai, H., Aubin, C. S., Mcmurry, J., and Martin, W. (2002). Immuno-informatics: mining genomes for vaccine components. Immunol. Cell Biol. 80, 255-269. doi: 10.1046/j.1440-1711.2002.01092.x

Dey, R., Dagur, P. K., Selvapandiyan, A., Mccoy, J. P., Salotra, P., Duncan, R., et al. (2013). Live attenuated Leishmania donovani p27 gene knockout parasites are nonpathogenic and elicit long-term protective immunity in BALB/c mice. J. Immunol. 190, 2138-2149. doi: 10.4049/jimmunol.1202801

Dikhit, M. R., Kumar, S., Vijaymahantesh, Sahoo, B. R., Mansuri, R., Amit, A., Yousuf Ansari, M., et al. (2015). Computational elucidation of potential antigenic CTL epitopes in Ebola virus. Infect. Genet. Evol. 36, 369-375. doi: 10.1016/j.meegid.2015.10.012

Ding, Z., Ou, R., Ni, B., Tang, J., and Xu, Y. (2013). Cytolytic activity of the human papillomavirus type 16 E711-20 epitope-specific cytotoxic T lymphocyte is enhanced by heat shock protein 110 in HLA- $A^{*} 0201$ transgenic mice. Clin. Vaccine Immunol. 20, 1027-1033. doi: 10.1128/CVI.00721-12

Doherty, T. M., and Coffman, R. L. (1996). Leishmania major: effect of infectious dose on T cell subset development in BALB/c mice. Exp. Parasitol. 84, 124-135. doi: 10.1006/expr.1996.0098

Doroud, D., and Rafati, S. (2012). Leishmaniasis: focus on the design of nanoparticulate vaccine delivery systems. Expert Rev. Vaccines 11, 69-86. doi: 10.1586/erv.11.166

Doroud, D., Zahedifard, F., Vatanara, A., Najafabadi, A. R., Taslimi, Y., Vahabpour, R., et al. (2011). Delivery of a cocktail DNA vaccine encoding cysteine proteinases type I, II and III with solid lipid nanoparticles potentiate protective immunity against Leishmania major infection. J. Control. Release 153, 154-162. doi: 10.1016/j.jconrel.2011.04.011

Dosset, M., Godet, Y., Vauchy, C., Beziaud, L., Lone, Y. C., Sedlik, C., et al. (2012). Universal cancer peptide-based therapeutic vaccine breaks tolerance against telomerase and eradicates established tumor. Clin. Cancer Res. 18, 6284-6295. doi: 10.1158/1078-0432.CCR-12-0896

Dunning, N. (2009). Leishmania vaccines: from leishmanization to the era of DNA technology. Biosci. Horiz. 2, 73-82. doi: 10.1093/biohorizons/hzp004

Elfaki, M. E., Khalil, E. A., De Groot, A. S., Musa, A. M., Gutierrez, A., Younis, B. M., et al. (2012). Immunogenicity and immune modulatory effects of in silico predicted $L$. donovani candidate peptide vaccines. Hum. Vaccin. Immunother. 8 , 1769-1774. doi: 10.4161/hv.21881

Eslami, N. S., Shokrgozar, M. A., Mousavi, A., Azadmanesh, K., Nomani, A., Apostolopoulos, V., et al. (2012). Simultaneous immunisation with a Wilms' tumour 1 epitope and its ubiquitin fusions results in enhanced cell mediated 
immunity and tumour rejection in C57BL/6 mice. Mol. Immunol. 51, 325-331. doi: 10.1016/j.molimm.2012.03.033

Etges, R. J., Bouvier, J., Hoffman, R., and Bordier, C. (1985). Evidence that the major surface proteins of three Leishmania species are structurally related. Mol. Biochem. Parasitol. 14, 141-149. doi: 10.1016/0166-6851(85)90033-7

Falk, K., Rötzschke, O., Stevanović, S., Jung, G., and Rammensee, H.-G. (1991). Allele-specific motifs revealed by sequencing of self-peptides eluted from MHC molecules. Nature 351, 290-296. doi: 10.1038/351290a0

Faria, D. R., Gollob, K. J., Barbosa, J. Jr., Schriefer, A., Machado, P. R., Lessa, H., et al. (2005). Decreased in situ expression of interleukin-10 receptor is correlated with the exacerbated inffammatory and cytotoxic responses observed in mucosal leishmaniasis. Infect. Immun. 73, 7853-7859. doi: 10.1128/IAI.73.12.7853-7859.2005

Faria, D. R., Souza, P. E., Duraes, F. V., Carvalho, E. M., Gollob, K. J., Machado, P. R., et al. (2009). Recruitment of CD8(+) T cells expressing granzyme A is associated with lesion progression in human cutaneous leishmaniasis. Parasite Immunol. 31, 432-439. doi: 10.1111/j.1365-3024.2009.01125.x

Gautam, S., Kumar, R., Singh, N., Singh, A. K., Rai, M., Sacks, D., et al. (2014). CD8 T cell exhaustion in human visceral leishmaniasis. J. Infect. Dis. 209, 290-299. doi: 10.1093/infdis/jit401

Gebhardt, T., Mueller, S. N., Heath, W. R., and Carbone, F. R. (2013). Peripheral tissue surveillance and residency by memory $\mathrm{T}$ cells. Trends Immunol. 34, 27-32. doi: 10.1016/j.it.2012.08.008

Geluk, A., Van Den Eeden, S., Van Meijgaarden, K., Dijkman, K., Franken, K., and Ottenhoff, T. (2012). A multistage-polyepitope vaccine protects against Mycobacterium tuberculosis infection in HLA-DR3 transgenic mice. Vaccine 30, 7513-7521. doi: 10.1016/j.vaccine.2012.10.045

Glennie, N. D., Yeramilli, V. A., Beiting, D. P., Volk, S. W., Weaver, C. T., and Scott, P. (2015). Skin-resident memory CD4+ T cells enhance protection against Leishmania major infection. J. Exp. Med. 212, 1405-1414. doi: 10.1084/jem.20142101

Gomes, R., Oliveira, F., Teixeira, C., Meneses, C., Gilmore, D. C., Elnaiem, D. E., et al. (2012). Immunity to sand fly salivary protein LJM11 modulates host response to vector-transmitted Leishmania conferring ulcer-free protection. J. Invest. Dermatol. 132, 2735-2743. doi: 10.1038/jid.2012.205

Goto, Y., Bhatia, A., Raman, V. S., Liang, H., Mohamath, R., Picone, A. F., et al. (2011). KSAC, the first defined polyprotein vaccine candidate for visceral leishmaniasis. Clin. Vaccine Immunol. 18, 1118-1124. doi: 10.1128/CVI. 05024-11

Griffiths, K. L., and Khader, S. A. (2014). Novel vaccine approaches for protection against intracellular pathogens. Curr. Opin. Immunol. 28, 58-63. doi: 10.1016/j.coi.2014.02.003

Guerfali, F. Z., Ben-Abdallah, H., Sghaier, R. M., Ben-Aissa, K., Mkannez, G., Attia, H., et al. (2009). An in silico immunological approach for prediction of $\mathrm{CD} 8+\mathrm{T}$ cell epitopes of Leishmania major proteins in susceptible BALB/c and resistant C57BL/6 murine models of infection. Infect. Genet. Evol. 9, 344-350. doi: 10.1016/j.meegid.2008.02.011

Gurunathan, S., Stobie, L., Prussin, C., Sacks, D. L., Glaichenhaus, N., Iwasaki, A., et al. (2000). Requirements for the maintenance of Th1 immunity in vivo following DNA vaccination: a potential immunoregulatory role for CD8 $+\mathrm{T}$ cells. J. Immunol. 165, 915-924. doi: 10.4049/jimmunol.165.2.915

He, Y., Rappuoli, R., De Groot, A. S., and Chen, R. T. (2010). Emerging vaccine informatics. J. Biomed. Biotechnol. 2010, 218590. doi: 10.1155/2010/218590

Henderson, D. A. (1997). Edward Jenner's vaccine. Public Health Rep. 112, 116121.

Heravi Shargh, V., Jaafari, M. R., Khamesipour, A., Jalali, S. A., Firouzmand, H., Abbasi, A., et al. (2012). Cationic liposomes containing soluble Leishmania antigens (SLA) plus CpG ODNs induce protection against murine model of leishmaniasis. Parasitol. Res. 111, 105-114. doi: 10.1007/s00436-0112806-5

Herrera-Najera, C., Piña-Aguilar, R., Xacur-Garcia, F., Ramirez-Sierra, M. J., and Dumonteil, E. (2009). Mining the Leishmania genome for novel antigens and vaccine candidates. Proteomics 9, 1293-1301. doi: 10.1002/pmic.2008 00533

Huang, F.-P., Xu, D., Esfandiari, E.-O., Sands, W., Wei, X.-Q., and Liew, F.Y. (1998). Cutting edge: mice defective in Fas are highly susceptible to Leishmania major infection despite elevated IL-12 synthesis, strong Th1 responses, and enhanced nitric oxide production. J. Immunol. 160, 4143-4147.
Huber, M., Timms, E., Mak, T. W., Rollinghoff, M., and Lohoff, M. (1998). Effective and long-lasting immunity against the parasite Leishmania major in CD8-deficient mice. Infect. Immun. 66, 3968-3970.

Huebener, N., Fest, S., Strandsby, A., Michalsky, E., Preissner, R., Zeng, Y., et al. (2008). A rationally designed tyrosine hydroxylase DNA vaccine induces specific antineuroblastoma immunity. Mol. Cancer Ther. 7, 2241-2251. doi: 10.1158/1535-7163.MCT-08-0109

Iborra, S., Soto, M., Carrión, J., Alonso, C., and Requena, J. M. (2004). Vaccination with a plasmid DNA cocktail encoding the nucleosomal histones of Leishmania confers protection against murine cutaneous leishmaniosis. Vaccine 22, 38653876.

Ip, P. P., Nijman, H. W., and Daemen, T. (2015). Epitope prediction assays combined with validation assays strongly narrows down putative cytotoxic $\mathrm{T}$ lymphocyte epitopes. Vaccines 3, 203-220. doi: 10.3390/vaccines3020203

Ivens, A. C., Peacock, C. S., Worthey, E. A., Murphy, L., Aggarwal, G., Berriman, M., et al. (2005). The genome of the kinetoplastid parasite, Leishmania major. Science 309, 436-442. doi: 10.1126/science.1112680

Jafarpour, N., Memarnejadian, A., Aghasadeghi, M. R., Kohram, F., Aghababa, H., Khoramabadi, N., et al. (2014). Clustered epitopes within a new poly-epitopic HIV-1 DNA vaccine shows immunogenicity in BALB/c mice. Mol. Biol. Rep. 41, 5207-5214. doi: 10.1007/s11033-014-3388-y

John, L., John, G. J., and Kholia, T. (2012). A reverse vaccinology approach for the identification of potential vaccine candidates from Leishmania spp. Appl. Biochem. Biotechnol. 167, 1340-1350. doi: 10.1007/s12010-012-9649-0

Joshi, T., Rodriguez, S., Perovic, V., Cockburn, I. A., and Stager, S. (2009). B7H1 blockade increases survival of dysfunctional CD8 (+) T cells and confers protection against Leishmania donovani infections. PLoS Pathog. 5:e1000431. doi: 10.1371/journal.ppat.1000431

Kamhawi, S., Aslan, H., and Valenzuela, J. G. (2014a). Vector saliva in vaccines for visceral leishmaniasis: a brief encounter of high consequence? Front. Public Health 2:99. doi: 10.3389/fpubh.2014.00099

Kamhawi, S., Oliveira, F., and Valenzuela, J. G. (2014b). Using humans to make a human leishmaniasis vaccine. Sci. Transl. Med. 6:234fs218. doi: 10.1126/scitranslmed.3009118

Katebi, A., Gholami, E., Taheri, T., Zahedifard, F., Habibzadeh, S., Taslimi, Y., et al. (2015). Leishmania tarentolae secreting the sand fly salivary antigen PpSP15 confers protection against Leishmania major infection in a susceptible BALB/c mice model. Mol. Immunol. 67, 501-511. doi: 10.1016/j.molimm.2015.08.001

Kedzierska, K., Curtis, J. M., Valkenburg, S. A., Hatton, L. A., Kiu, H., Doherty, P. C., et al. (2012). Induction of protective CD4+ T cell-mediated immunity by a Leishmania peptide delivered in recombinant influenza viruses. PLoS ONE 7:e33161. doi: 10.1371/journal.pone.0033161

Kishore, K., Kumar, V., Kesari, S., Dinesh, D. S., Kumar, A. J., Das, P., et al. (2006). Vector control in leishmaniasis. Indian J. Med. Res. 123, 467-472.

Kotturi, M. F., Assarsson, E., Peters, B., Grey, H., Oseroff, C., Pasquetto, V., et al. (2009). Of mice and humans: how good are HLA transgenic mice as a model of human immune responses? Immunome Res. 5, 3. doi: 10.1186/1745-7580-5-3

Kumar, R., Bumb, R. A., and Salotra, P. (2009). Correlation of parasitic load with interleukin-4 response in patients with cutaneous leishmaniasis due to Leishmania tropica. FEMS Immunol. Med. Microbiol. 57, 239-246. doi: 10.1111/j.1574-695X.2009.00607.x

Li, X., Yang, X., Jiang, Y., and Liu, J. (2005). A novel HBV DNA vaccine based on $\mathrm{T}$ cell epitopes and its potential therapeutic effect in HBV transgenic mice. Int. Immunol. 17, 1293-1302. doi: 10.1093/intimm/dxh305

Liao, W. W., and Arthur, J. W. (2011). Predicting peptide binding to major histocompatibility complex molecules. Autoimmun. Rev. 10, 469-473. doi: 10.1016/j.autrev.2011.02.003

Liu, D., and Uzonna, J. E. (2012). The early interaction of Leishmania with macrophages and dendritic cells and its influence on the host immune response. Front. Cell. Infect. Microbiol. 2:83. doi: 10.3389/fcimb.2012.00083

Llanos-Cuentas, A., Calderón, W., Cruz, M., Ashman, J. A., Alves, F. P., Coler, R. N., et al. (2010). A clinical trial to evaluate the safety and immunogenicity of the LEISH-F1+ MPL-SE vaccine when used in combination with sodium stibogluconate for the treatment of mucosal leishmaniasis. Vaccine 28, 74277435. doi: 10.1016/j.vaccine.2010.08.092

Lu, J., Higashimoto, Y., Appella, E., and Celis, E. (2004). Multiepitope Trojan antigen peptide vaccines for the induction of antitumor CTL and Th immune responses. J. Immunol. 172, 4575-4582. doi: 10.4049/jimmunol.172.7.4575 
Luo, H., Ye, H., Ng, H. W., Shi, L., Tong, W., Mendrick, D. L., et al. (2015). Machine Learning Methods for Predicting HLA-Peptide Binding Activity. Bioinform. Biol. Insights 9, 21-29. doi: 10.4137/BBI.S29466

Mahajan, B., Berzofsky, J. A., Boykins, R. A., Majam, V., Zheng, H., Chattopadhyay, R., et al. (2010). Multiple antigen peptide vaccines against Plasmodium falciparum malaria. Infect. Immun. 78, 4613-4624. doi: 10.1128/IAI.00533-10

McMahon-Pratt, D., and Alexander, J. (2004). Does the Leishmania major paradigm of pathogenesis and protection hold for New World cutaneous leishmaniases or the visceral disease? Immunol. Rev. 201, 206-224. doi: 10.1111/j.0105-2896.2004.00190.x

Mendez, S., Gurunathan, S., Kamhawi, S., Belkaid, Y., Moga, M. A., Skeiky, Y. A., et al. (2001). The potency and durability of DNA- and protein-based vaccines against Leishmania major evaluated using low-dose, intradermal challenge. J. Immunol. 166, 5122-5128. doi: 10.4049/jimmunol.166.8.5122

Menon, J. N., and Bretscher, P. A. (1996). Characterization of the immunological memory state generated in mice susceptible to Leishmania major following exposure to low doses of $L$. major and resulting in resistance to a normally pathogenic challenge. Eur. J. Immunol. 26, 243-249. doi: 10.1002/eji.1830260138

Mogk, A., Schmidt, R., and Bukau, B. (2007). The N-end rule pathway for regulated proteolysis: prokaryotic and eukaryotic strategies. Trends Cell Biol. 17, 165-172. doi: $10.1016 /$ j.tcb.2007.02.001

Mohajery, M., Shamsian, A., and Mahmoodi, M. (2007). Tc1 Cells percentage in patients with cutaneous leishmaniasis before and after treatment with Glucantime. Iran. J. Public Health 36, 55-61.

Moise, L., Buller, R. M., Schriewer, J., Lee, J., Frey, S. E., Weiner, D. B., et al. (2011). VennVax, a DNA-prime, peptide-boost multi-T-cell epitope poxvirus vaccine, induces protective immunity against vaccinia infection by $\mathrm{T}$ cell response alone. Vaccine 29, 501-511. doi: 10.1016/j.vaccine.2010.10.064

Momeni, A. Z., Jalayer, T., Emamjomeh, M., Khamesipour, A., Zicker, F., Ghassemi, R. L., et al. (1999). A randomised, double-blind, controlled trial of a killed L. major vaccine plus BCG against zoonotic cutaneous leishmaniasis in Iran. Vaccine 17, 466-472. doi: 10.1016/S0264-410X(98)00220-5

Moriel, D. G., Scarselli, M., Serino, L., Mora, M., Rappuoli, R., and Masignani, V. (2008). Genome-based vaccine development: a short cut for the future. Hum. Vaccin. 4, 184-188. doi: 10.4161/hv.4.3.6313

Muller, I. (1992). Role of T cell subsets during the recall of immunologic memory to Leishmania major. Eur. J. Immunol. 22, 3063-3069. doi: 10.1002/eji.1830221206

Murray, H. W., Lu, C. M., Mauze, S., Freeman, S., Moreira, A. L., Kaplan, G., et al. (2002). Interleukin-10 (IL-10) in experimental visceral leishmaniasis and IL10 receptor blockade as immunotherapy. Infect. Immun. 70, 6284-6293. doi: 10.1128/IAI.70.11.6284-6293.2002

Mutiso, J. M., Macharia, J. C., Kiio, M. N., Ichagichu, J. M., Rikoi, H., and Gicheru, M. M. (2013). Development of Leishmania vaccines: predicting the future from past and present experience. J. Biomed. Res. 27, 85-102. doi: 10.7555/JBR.27.20120064

Nadim, A., Javadian, E., Tahvildar-Bidruni, G., and Ghorbani, M. (1983). Effectiveness of leishmanization in the control of cutaneous leishmaniasis. Bull. Soc. Pathol. Exot. Filiales 76, 377-383.

Naouar, I., Boussoffara, T., Chenik, M., Gritli, S., Ahmed, M. B., Hmida, N. B., et al. (2016). Prediction of $\mathrm{T}$ cell epitopes from Leishmania major potentially excreted/secreted proteins inducing granzyme B production. PLoS ONE 11:e0147076. doi: 10.1371/journal.pone.0147076

Neisig, A., Roelse, J., Sijts, A., Ossendorp, F., Feltkamp, M., Kast, W. M., et al. (1995). Major differences in transporter associated with antigen presentation (TAP)-dependent translocation of MHC class I-presentable peptides and the effect of flanking sequences. J. Immunol. 154, 1273-1279.

Noazin, S., Modabber, F., Khamesipour, A., Smith, P. G., Moulton, L. H., Nasseri, K., et al. (2008). First generation leishmaniasis vaccines: a review of field efficacy trials. Vaccine 26, 6759-6767. doi: 10.1016/j.vaccine.2008.09.085

Novais, F. O., Carvalho, L. P., Graff, J. W., Beiting, D. P., Ruthel, G., Roos, D. S., et al. (2013). Cytotoxic T cells mediate pathology and metastasis in cutaneous leishmaniasis. PLoS Pathog. 9:e1003504. doi: 10.1371/journal.ppat.1003504

Nylen, S., and Eidsmo, L. (2012). Tissue damage and immunity in cutaneous leishmaniasis. Parasite Immunol. 34, 551-561. doi: 10.1111/pim.12007

Nylen, S., Maurya, R., Eidsmo, L., Manandhar, K. D., Sundar, S., and Sacks, D. (2007). Splenic accumulation of IL-10 mRNA in T cells distinct from
CD4+CD25+ (Foxp3) regulatory $\mathrm{T}$ cells in human visceral leishmaniasis. J. Exp. Med. 204, 805-817. doi: 10.1084/jem.20061141

Okwor, I., and Uzonna, J. E. (2013). The immunology of Leishmania/HIV co-infection. Immunol. Res. 56, 163-171. doi: 10.1007/s12026-0138389-8

Okwor, I. B., Jia, P., Mou, Z., Onyilagha, C., and Uzonna, J. E. (2014). CD8+ T cells are preferentially activated during primary low dose Leishmania major infection but are completely dispensable during secondary anti-Leishmania immunity. PLoS Negl. Trop. Dis. 8:e3300. doi: 10.1371/journal.pntd.00 03300

Oliveira, F., Rowton, E., Aslan, H., Gomes, R., Castrovinci, P. A., Alvarenga, P. H., et al. (2015). A sand fly salivary protein vaccine shows efficacy against vectortransmitted cutaneous leishmaniasis in nonhuman primates. Sci. Transl. Med. 7:290ra290. doi: 10.1126/scitranslmed.aaa3043

Paape, D., and Aebischer, T. (2011). Contribution of proteomics of Leishmania spp. to the understanding of differentiation, drug resistance mechanisms, vaccine and drug development. J. Proteomics 74, 1614-1624. doi: 10.1016/j.jprot.2011.05.005

Pagan, A. J., Peters, N. C., Debrabant, A., Ribeiro-Gomes, F., Pepper, M., Karp, C. L., et al. (2013). Tracking antigen-specific CD4+ T cells throughout the course of chronic Leishmania major infection in resistant mice. Eur. J. Immunol. 43, 427-438. doi: 10.1002/eji.201242715

Park, A. Y., Hondowicz, B. D., and Scott, P. (2000). IL-12 is required to maintain a Th1 response during Leishmania major infection. J. Immunol. 165, 896-902. doi: 10.4049/jimmunol.165.2.896

Pascolo, S. (2005). HLA class I transgenic mice: development, utilisation and improvement. Expert Opin. Biol. Ther. 5, 919-938. doi: 10.1517/14712598.5.7.919

Patronov, A., and Doytchinova, I. (2013). T-cell epitope vaccine design by immunoinformatics. Open Biol. 3, 120139. doi: 10.1098/rsob.120139

Peacock, C. S., Seeger, K., Harris, D., Murphy, L., Ruiz, J. C., Quail, M. A., et al. (2007). Comparative genomic analysis of three Leishmania species that cause diverse human disease. Nat. Genet. 39, 839-847. doi: 10.1038/ng2053

Peters, N. C., Bertholet, S., Lawyer, P. G., Charmoy, M., Romano, A., RibeiroGomes, F. L., et al. (2012). Evaluation of recombinant Leishmania polyprotein plus glucopyranosyl lipid A stable emulsion vaccines against sand flytransmitted Leishmania major in C57BL/6 mice. J. Immunol. 189, 4832-4841. doi: 10.4049/jimmunol.1201676

Peters, N. C., Kimblin, N., Secundino, N., Kamhawi, S., Lawyer, P., and Sacks, D. L. (2009). Vector transmission of Leishmania abrogates vaccine-induced protective immunity. PLoS Pathog. 5:e1000484. doi: 10.1371/journal.ppat.1000484

Peters, N. C., Pagan, A. J., Lawyer, P. G., Hand, T. W., Henrique Roma, E., Stamper, L. W., et al. (2014). Chronic parasitic infection maintains high frequencies of short-lived Ly6C+CD4+ effector T cells that are required for protection against re-infection. PLoS Pathog. 10:e1004538. doi: 10.1371/journal.ppat. 1004538

Pompeu, M. M., Brodskyn, C., Teixeira, M. J., Clarencio, J., Van Weyenberg, J., Coelho, I. C., et al. (2001). Differences in gamma interferon production in vitro predict the pace of the in vivo response to Leishmania amazonensis in healthy volunteers. Infect. Immun. 69, 7453-7460. doi: 10.1128/IAI.69.12.74537460.2001

Rafati, S., Nakhaee, A., Taheri, T., Taslimi, Y., Darabi, H., Eravani, D., et al. (2005). Protective vaccination against experimental canine visceral leishmaniasis using a combination of DNA and protein immunization with cysteine proteinases type I and II of L. infantum. Vaccine 23, 3716-3725. doi: $10.1016 / j . v a c c i n e .2005 .02 .009$

Rafati, S., Salmanian, A.-H., Hashemi, K., Schaff, C., Belli, S., and Fasel, N. (2001). Identification of Leishmania major cysteine proteinases as targets of the immune response in humans. Mol. Biochem. Parasitol. 113, 35-43. doi: 10.1016/S0166-6851(00)00377-7

Rafati, S., Zahedifard, F., and Nazgouee, F. (2006). Prime-boost vaccination using cysteine proteinases type I and II of Leishmania infantum confers protective immunity in murine visceral leishmaniasis. Vaccine 24, 2169-2175. doi: 10.1016/j.vaccine.2005.11.011

Raju, S., and Rao, V. (2010). Current developmemt strategies for vaccines and the role of reverse vaccinology. J. Pharm. Res. Health Care 2, 339-346. doi: 10.18311/ajprhc/2010/584 
Raman, V. S., Duthie, M. S., Fox, C. B., Matlashewski, G., and Reed, S. G. (2012). Adjuvants for Leishmania vaccines: from models to clinical application. Front. Immunol. 3:144. doi: 10.3389/fimmu.2012.00144

Ramírez, L., Santos, D. M., Souza, A. P., Coelho, E. A., Barral, A., Alonso, C., et al. (2013). Evaluation of immune responses and analysis of the effect of vaccination of the Leishmania major recombinant ribosomal proteins L3 or L5 in two different murine models of cutaneous leishmaniasis. Vaccine 31, 1312-1319. doi: 10.1016/j.vaccine.2012.12.071

Rammensee, H.-G., Bachmann, J., Emmerich, N. P. N., Bachor, O. A., and Stevanović, S. (1999). SYFPEITHI: database for MHC ligands and peptide motifs. Immunogenetics 50, 213-219. doi: 10.1007/s002510050595

Rappuoli, R. (2007). Bridging the knowledge gaps in vaccine design. Nat. Biotechnol. 25, 1361-1366. doi: 10.1038/nbt1207-1361

Rappuoli, R., and Aderem, A. (2011). A 2020 vision for vaccines against HIV, tuberculosis and malaria. Nature 473, 463-469. doi: 10.1038/nature10124

Raymond, F., Boisvert, S., Roy, G., Ritt, J. F., Legare, D., Isnard, A., et al. (2012). Genome sequencing of the lizard parasite Leishmania tarentolae reveals loss of genes associated to the intracellular stage of human pathogenic species. Nucleic Acids Res. 40, 1131-1147. doi: 10.1093/nar/gkr834

Reche, P. A., and Reinherz, E. L. (2007). "Definition of MHC supertypes through clustering of MHC peptide-binding repertoires," in Immunoinformatics, ed. D. R. Flower (New York, NY: Springer), 163-173.

Reithinger, R., Dujardin, J. C., Louzir, H., Pirmez, C., Alexander, B., and Brooker, S. (2007). Cutaneous leishmaniasis. Lancet Infect. Dis. 7, 581-596. doi: 10.1016/S1473-3099(07)70209-8

Resende, D. M., Rezende, A. M., Oliveira, N. J., Batista, I. C., Correa-Oliveira, R., Reis, A. B., et al. (2012). An assessment on epitope prediction methods for protozoa genomes. BMC Bioinformatics 13:309. doi: 10.1186/1471-2105-13-309

Rezvan, H. (2013). Immunogenicity of HLA-DR1 restricted peptides derived from Leishmania major gp63 using FVB/N-DR1 transgenic mouse model. Iran. J. Parasitol. 8, 273-279.

Rezvan, H., Rees, R., and Ali, S. (2012). Immunogenicity of MHC class I peptides derived from Leishmania mexicana Gp63 in HLA-A2.1 transgenic (HHDII) and BALB/C mouse models. Iran. J. Parasitol. 7, 27-40.

Riede, O., Seifert, K., Oswald, D., Endmann, A., Hock, C., Winkler, A., et al. (2015). Preclinical safety and tolerability of a repeatedly administered human leishmaniasis DNA vaccine. Gene Ther. 22, 628-635. doi: 10.1038/gt.2015.35

Rinaudo, C. D., Telford, J. L., Rappuoli, R., and Seib, K. L. (2009). Vaccinology in the genome era. J. Clin. Invest. 119, 2515-2525. doi: 10.1172/ JCI38330

Rodrigues, J. C. F., Godinho, J. L. P., and De Souza, W. (2014). "Biology of human pathogenic trypanosomatids: epidemiology, lifecycle and ultrastructure," in Proteins and Proteomics of Leishmania and Trypanosoma, eds A. L. S. Santos, M. H. Branquinha, C. M. d'Avila-Levy, L. F. Kneipp, and C. L. Sodré (New York, NY: Springer), 1-42.

Romano, A., Doria, N. A., Mendez, J., Sacks, D. L., and Peters, N. C. (2015). Cutaneous infection with Leishmania major mediates heterologous protection against visceral infection with Leishmania infantum. J. Immunol. 195, 38163827. doi: 10.4049/jimmunol.1500752

Sachdeva, R., Banerjea, A. C., Malla, N., and Dubey, M. L. (2009). Immunogenicity and efficacy of single antigen Gp63, polytope and polytopeHSP70 DNA vaccines against visceral Leishmaniasis in experimental mouse model. PLoS ONE 4:e7880. doi: 10.1371/journal.pone.0007880

Saffari, B., and Mohabatkar, H. (2009). Computational analysis of cysteine proteases (Clan CA, Family $\mathrm{Cl}$ ) of Leishmania major to find potential epitopic regions. Genomics Proteomics Bioinform. 7, 87-95. doi: 10.1016/S16720229(08)60037-6

Saha, S., Mondal, S., Ravindran, R., Bhowmick, S., Modak, D., Mallick, S., et al. (2007). IL-10- and TGF-beta-mediated susceptibility in kala-azar and post-kalaazar dermal leishmaniasis: the significance of amphotericin B in the control of Leishmania donovani infection in India. J. Immunol. 179, 5592-5603. doi: 10.4049/jimmunol.179.8.5592

Saljoughian, N., Taheri, T., and Rafati, S. (2014). Live vaccination tactics: possible approaches for controlling visceral leishmaniasis. Front. Immunol. 5:134. doi: 10.3389/fimmu.2014.00134

Saljoughian, N., Taheri, T., Zahedifard, F., Taslimi, Y., Doustdari, F., Bolhassani, A., et al. (2013). Development of novel prime-boost strategies based on a trigene fusion recombinant $L$. tarentolae vaccine against experimental murine visceral leishmaniasis. PLoS Negl. Trop. Dis. 7:e2174. doi: 10.1371/journal.pntd. 0002174

Santos Cda, S., Boaventura, V., Ribeiro Cardoso, C., Tavares, N., Lordelo, M. J., Noronha, A., et al. (2013). CD8(+) granzyme B(+)-mediated tissue injury vs. CD4(+)IFNgamma(+)-mediated parasite killing in human cutaneous leishmaniasis. J. Invest. Dermatol. 133, 1533-1540. doi: 10.1038/jid.2013.4

Schroeder, J., and Aebischer, T. (2011). Vaccines for leishmaniasis: from proteome to vaccine candidates. Hum. Vaccin. 7(Suppl.), 10-15. doi: 10.4161/hv.7.0.14556

Seib, K. L., Dougan, G., and Rappuoli, R. (2009). The key role of genomics in modern vaccine and drug design for emerging infectious diseases. PLoS Genet. 5:e1000612. doi: 10.1371/journal.pgen.1000612

Selvapandiyan, A., Dey, R., Nylen, S., Duncan, R., Sacks, D., and Nakhasi, H. L. (2009). Intracellular replication-deficient Leishmania donovani induces long lasting protective immunity against visceral leishmaniasis. J. Immunol. 183, 1813-1820. doi: 10.4049/jimmunol.0900276

Seyed, N., Taheri, T., Vauchy, C., Dosset, M., Godet, Y., Eslamifar, A., et al. (2014). Immunogenicity evaluation of a rationally designed polytope construct encoding HLA-A ${ }^{*} 0201$ restricted epitopes derived from Leishmania major related proteins in HLA-A2/DR1 transgenic mice: steps toward polytope vaccine. PLoS ONE 9:e108848. doi: 10.1371/journal.pone.0108848

Seyed, N., Zahedifard, F., Safaiyan, S., Gholami, E., Doustdari, F., Azadmanesh, K., et al. (2011). In silico analysis of six known Leishmania major antigens and in vitro evaluation of specific epitopes eliciting HLA-A2 restricted CD8 T cell response. PLoS Negl. Trop. Dis. 5:e1295. doi: 10.1371/journal.pntd. 0001295

Shahbazi, M., Zahedifard, F., Saljoughian, N., Doroud, D., Jamshidi, S., Mahdavi, N., et al. (2015a). Immunological comparison of DNA vaccination using two delivery systems against canine leishmaniasis. Vet. Parasitol. 212, 130-139. doi: 10.1016/j.vetpar.2015.07.005

Shahbazi, M., Zahedifard, F., Taheri, T., Taslimi, Y., Jamshidi, S., Shirian, S., et al. (2015b). Evaluation of live recombinant nonpathogenic Leishmania tarentolae expressing cysteine proteinase and A2 genes as a candidate vaccine against experimental canine visceral leishmaniasis. PLoS ONE 10:e0132794. doi: 10.1371/journal.pone.0132794

Sharma, A., and Madhubala, R. (2009). Ubiquitin conjugation of open reading frame F DNA vaccine leads to enhanced cell-mediated immune response and induces protection against both antimony-susceptible andresistant strains of Leishmania donovani. J. Immunol. 183, 7719-7731. doi: 10.4049/jimmunol.0900132

Shipo Wu, T. Y., Song, X., Yi, S., Hou, L., and Chen, W. (2012). Prediction and identification of mouse cytotoxic $\mathrm{T}$ lymphocyte epitopes in Ebola virus glycoproteins. Virol. J. 9, 111. doi: 10.1186/1743-422X-9-111

Silvestre, R., Cordeiro-Da-Silva, A., and Ouaissi, A. (2008). Live attenuated Leishmania vaccines: a potential strategic alternative. Arch. Immunol. Ther. Exp. 56, 123-126. doi: 10.1007/s00005-008-0010-9

Singh, O. P., Gidwani, K., Kumar, R., Nylen, S., Jones, S. L., Boelaert, M., et al. (2012). Reassessment of immune correlates in human visceral leishmaniasis as defined by cytokine release in whole blood. Clin. Vaccine Immunol. 19, 961-966. doi: 10.1128/CVI.00143-12

Singh, S. P., Roopendra, K., and Mishra, B. N. (2015). Genome-wide prediction of vaccine candidates for Leishmania major: an integrated approach. J. Trop. Med. 2015:709216. doi: 10.1155/2015/709216

Skeiky, Y. A., Coler, R. N., Brannon, M., Stromberg, E., Greeson, K., Crane, R. T., et al. (2002). Protective efficacy of a tandemly linked, multi-subunit recombinant leishmanial vaccine (Leish-111f) formulated in MPL adjuvant. Vaccine 20, 3292-3303. doi: 10.1016/S0264-410X(02)00302-X

Slingluff, C. L. Jr. (2011). The present and future of peptide vaccines for cancer: single or multiple, long or short, alone or in combination? Cancer J. 17, 343-350. doi: 10.1097/PPO.0b013e318233e5b2

Spath, G. F., Lye, L. F., Segawa, H., Turco, S. J., and Beverley, S. M. (2004). Identification of a compensatory mutant (lpg2-REV) of Leishmania major able to survive as amastigotes within macrophages without LPG2-dependent glycoconjugates and its significance to virulence and immunization strategies. Infect. Immun. 72, 3622-3627. doi: 10.1128/IAI.72.6.36223627.2004

Spitzer, N., Jardim, A., Lippert, D., and Olafson, R. W. (1999). Long-term protection of mice against Leishmania major with a synthetic peptide vaccine. Vaccine 17, 1298-1300. doi: 10.1016/S0264-410X(98)00363-6 
Stäger, S., Alexander, J., Carter, K. C., Brombacher, F., and Kaye, P. M. (2003). Both Interleukin-4 (IL-4) and IL-4 receptor signaling contribute to the development of hepatic granulomas with optimal antileishmanial activity. Infect. Immun. 71, 4804-4807. doi: 10.1128/IAI.71.8.4804-4807.2003

Stober, C., Lange, U., Roberts, M., Gilmartin, B., Francis, R., Almeida, R., et al. (2006). From genome to vaccines for leishmaniasis: screening 100 novel vaccine candidates against murine Leishmania major infection. Vaccine 24, 2602-2616. doi: $10.1016 /$ j.vaccine.2005.12.012

Taheri, T., and Rafati, S. (2013). Leishmaniasis: recombinant DNA vaccination and different approaches for vaccine development. Clin. Invest. 3, 1023-1044. doi: 10.4155/cli.13.99

Tang, S. T., Van Meijgaarden, K. E., Caccamo, N., Guggino, G., Klein, M. R., Van Weeren, P., et al. (2011). Genome-based in silico identification of new Mycobacterium tuberculosis antigens activating polyfunctional CD8+ $\mathrm{T}$ cells in human tuberculosis. J. Immunol. 186, 1068-1080. doi: 10.4049/jimmunol.1002212

Teh-Poot, C., Tzec-Arjona, E., Martinez-Vega, P., Ramirez-Sierra, M. J., RosadoVallado, M., and Dumonteil, E. (2015). From genome screening to creation of vaccine against Trypanosoma cruzi by use of immunoinformatics. J. Infect. Dis. 211, 258-266. doi: 10.1093/infdis/jiu418

Tomar, N., and De, R. K. (2010). Immunoinformatics: an integrated scenario. Immunology 131, 153-168. doi: 10.1111/j.1365-2567.2010. 03330.x

Tsagozis, P., Karagouni, E., and Dotsika, E. (2003). CD8(+) T cells with parasitespecific cytotoxic activity and a Tc1 profile of cytokine and chemokine secretion develop in experimental visceral leishmaniasis. Parasite Immunol. 25, 569-579. doi: 10.1111/j.0141-9838.2004.00672.x

Uzonna, J. E., Joyce, K. L., and Scott, P. (2004). Low dose Leishmania major promotes a transient $\mathrm{T}$ helper cell type 2 response that is down-regulated by interferon $\gamma$-producing CD8+ T cells. J. Exp. Med. 199, 1559-1566. doi: 10.1084/jem.20040172

Uzonna, J. E., Wei, G., Yurkowski, D., and Bretscher, P. (2001). Immune elimination of Leishmania major in mice: implications for immune memory, vaccination, and reactivation disease. J. Immunol. 167, 6967-6974. doi: 10.4049/jimmunol.167.12.6967

von Stebut, E. (2007). Cutaneous Leishmania infection: progress in pathogenesis research and experimental therapy. Exp. Dermatol. 16, 340-346. doi: 10.1111/j.1600-0625.2007.00554.x

Wang, Z. E., Reiner, S. L., Hatam, F., Heinzel, F. P., Bouvier, J., Turck, C. W., et al. (1993). Targeted activation of CD8 cells and infection of beta 2-microglobulin- deficient mice fail to confirm a primary protective role for CD8 cells in experimental leishmaniasis. J. Immunol. 151, 2077-2086.

Webb, J. R., Campos-Neto, A., Ovendale, P. J., Martin, T. I., Stromberg, E. J., Badaro, R., et al. (1998). Human and murine immune responses to a novel Leishmania major recombinant protein encoded by members of a multicopy gene family. Infect. Immun. 66, 3279-3289.

Yu, K., Petrovsky, N., Schonbach, C., Koh, J. Y., and Brusic, V. (2002). Methods for prediction of peptide binding to MHC molecules: a comparative study. Mol. Med. 8, 137-148.

Zahedifard, F., Gholami, E., Taheri, T., Taslimi, Y., Doustdari, F., Seyed, N., et al. (2014). Enhanced protective efficacy of nonpathogenic recombinant Leishmania tarentolae expressing cysteine proteinases combined with a sand fly salivary antigen. PLoS Negl. Trop. Dis. 8:e2751. doi: 10.1371/journal.pntd.0002751

Zandieh, M., Kashi, T., Taheri, T., Zahedifard, F., and Taslimi, Y. (2015). Assessment of protection induced by DNA and live vaccine encoding Leishmania MHC class I restricted epitopes against L. major challenge in Balb/c mice model. J. Microb. Biochem. Technol. 7, 427-438. doi: 10.4172/19485948.1000250

Zaph, C., Uzonna, J., Beverley, S. M., and Scott, P. (2004). Central memory T cells mediate long-term immunity to Leishmania major in the absence of persistent parasites. Nat. Med. 10, 1104-1110. doi: 10.1038/nm1108

Zijlstra, E., Musa, A., Khalil, E., El Hassan, I., and El-Hassan, A. (2003). Postkala-azar dermal leishmaniasis. Lancet Infect. Dis. 3, 87-98. doi: 10.1016/S14733099(03)00517-6

Conflict of Interest Statement: The authors declare that the research was conducted in the absence of any commercial or financial relationships that could be construed as a potential conflict of interest.

The reviewer SS and handling Editor declared their shared affiliation, and the handling Editor states that the process nevertheless met the standards of a fair and objective review.

Copyright (C) 2016 Seyed, Taheri and Rafati. This is an open-access article distributed under the terms of the Creative Commons Attribution License (CC BY). The use, distribution or reproduction in other forums is permitted, provided the original author(s) or licensor are credited and that the original publication in this journal is cited, in accordance with accepted academic practice. No use, distribution or reproduction is permitted which does not comply with these terms. 